\title{
Organizational change readiness and manager' behavior in managing change
}

\author{
Gehan Mohammed Diab*, Sanaa M. Safan, Huda M. Bakeer \\ Faculty of Nursing, Menofia University, Menofia, Egypt
}

Received: December 10, 2017

Accepted: February 1, 2018

Online Published: March 7, 2018

DOI: $10.5430 /$ jnep.v8n7p68

URL: https://doi.org/10.5430/jnep.v8n7p68

\begin{abstract}
Background and objective: Organizational readiness refers to organizational members' change commitment and change efficacy to implement organizational change and confidence in their accumulative abilities to do so. The aim of the study was to assess the nurse managers' behavior in managing change, and the level of the organizational change readiness at selected hospitals at Menofia Governorate.

Methods: Design: A descriptive cross-sectional design was used. Setting: The study was conducted at two hospitals, namely University Hospital and Shebin El-Kom Teaching Hospital, in Menofia Governorate, Egypt. Subjects: It consisted of two groups, Group 1: A convenience sample of 136 staff nurses (67 staff nurses from Menofia University Hospital, and 69 from Shebin El-Kom Teaching Hospital), Group 2: All nurse manager available on the time of the study (31 from Menofia University Hospitals, and 30 from Shebin El-Kom Teaching Hospital). Tools: a) Tool one: Change management process Questionnaire, b) Tool two: Change Readiness Assessment Scale.

Results: More than half of the nurse managers reported that they have a good behavior in managing change in the organization, while the staff nurses reported that their managers had a bad behavior during the change process. Organizational readiness level was higher in University hospitals than in Teaching hospital as perceived by the study subjects.

Conclusions: The nurse managers and staff nurses reported that the organization had a bad readiness level to change. Additionally there was a positive correlation between organizational readiness and manager behavior in managing change. Recommendations: Organization should have a readiness for change to support the change process by possessing the right resources and conditions, a clear insights and goals for the intended change and have the inventiveness, behavior to participate with the change and develop work. Also, agents of change chiefs and management must need to drive a strong reaction for change from the stakeholders that leads to highest performance improvement.
\end{abstract}

Key Words: Change readiness, Managing change, Manager behavior

\section{INTRODUCTION}

The century we are living in remains for quicken rate of progress. Change in healthcare organizations nowadays is the norm rather than stability. Therefore, the ability of the organization to change and adapt is very critical for success. ${ }^{[1]}$ Change is considered among the significant attributes of social, political and monetary frameworks and the accomplishment of an organization to keep up its reality is disclosed by its capacity to change. ${ }^{[2]}$

Change is a continuous dynamic process. To be a successful organization, the change should take place and be carried

\footnotetext{
*Correspondence: Gehan Mohammed Diab, Assistant professor; Email: diabgehan@yahoo.com; Address: Faculty of Nursing, Menofia University, Menofia, Egypt.
} 
out in three different categories, namely; individual, group and organization. In each category of progress, leadership plays its diverse role, as its primary duty is to engage with people and challenge their efforts to be their greatest efforts in support of an organizational change. Change management is a key area for stabilization for the sound development of an organization. Effective change in any association is difficult with no dynamic management support. ${ }^{[3]}$

To get together with the challenges, organizations are necessary to be rehabilitated into learning organizations at first stage, in order to become a superlative organization. For making the change from a traditional organization into a learning organization, the major essential core is leadership which illuminates the insights and goals of the organization, help workers toward finish their objectives and assists them to establish the inventive and learning condition. ${ }^{[4]}$

Change management is really an essential arrangement in planning for the organization to move from its actual state to a coveted future state. The organizational change means a planned activity that serves as a connection between the diverse parts of a change process, set up priorities and timelines, assigning farm duties, establishing mechanisms for evaluation and adjustment where necessary. To be effective in managing change, it is mandatory to be suitably planned. Successful planning for change must start a long time previous to changes take effect and consultation should occur. ${ }^{[5]}$

Organizational change occurs when an organization makes a progress from its present state to some coveted future state. Managing organizational change is the process of planning and implementing change in organizations in such a way as to minimize employee resistance and cost to the organization while all the while amplifying the adequacy of the change exertion. Accordingly, Readiness for the change is required in order to decrease resistance to change. ${ }^{[6]}$ Readiness to change is defined as a mental condition of feeling resolved to change and having the capacity to change behavior towards a coveted result. Readiness to change is a multi-faceted concept that has been already utilized as a part of designing educational interventions. ${ }^{[7]}$

Organizational readiness for change is a multi-level, multifaceted develop. As an organization-level construct, preparation for change refers to organizational members' shared resolve to implement a change (change commitment) and shared confidence in their aggregate capacity to do as such (change efficacy). Organizational preparation for change differs as a function of how much organizational member's value the change and how positively they evaluate three key determinants of implementation capability: task demands, resource availability, and situational factors. At the point when organizational readiness for change is high, organizational members will probably start change, exert greater effort, exhibit greater persistence, and display more cooperative behavior. The result is more. ${ }^{[8]}$

The reason for a change readiness assessment is to examine the level of readiness of the conditions, attitudes, and resources at all levels in a system. In this context, the word 'system' is being utilized to cover organizations, sectors, networks, national structures, or any other combination of elements that may together be the focus of a capacity development initiative required for the change to happen effectively. The more the complexity of the proposed change, the more prominent the significance of understanding whether and where there is readiness for change as this can be basic first to decide whether it is suitable to intervene and, if it is appropriate, about both the entry points and the types of intervention. ${ }^{[9]}$

All together for an organization to adjust to the changes around, it is vital for it to adopt an effective leadership approach besides being organized and making organizational arrangements. ${ }^{[10]}$ Leadership is also a spirit for the manager to capture employee back into work and to deliver most extreme benefits from change. ${ }^{[11]}$

Managers may need to convey "results" and therefore are not totally free in their decisions. In any case, they settle on decisions on quite a rational basis--seen from their viewpoint. Henceforth, many managers in the same way as other individuals make decisions first with regard to their personal interests (in the West, at least), to their own position and career aspirations, to their families and social affairs. These personal interests usually fit group interests, i.e. to strengthen the roles, position, and impact of managers (in comparison and against other professions, lower ranks or external stakeholders). Strategic change initiatives discourses about strategy, change, and other management issues provide excellent opportunities for senior and middle managers to set the plan, to get their belief system through as the organization's primary strategic objectives, to strengthen their role and position, to keep, gain or increase internal influence. ${ }^{[12]}$

\subsection{Significance of the study}

Adaptation to change has turned into a typical plan for organizations of all types of health care. The creation and design of change processes within an organization is frequently a role of the leaders inside it. Managers and supervisors assume a key role because of the relationship they have with workers inside the organization. Furthermore, there is strong evidence that the manager of the unit may impact the speed and effectiveness with which new processes can be implemented. 
So, the present study was conducted to study the behavior of the nurse managers during the change process and the level of the organizational change readiness in different hospitals in Menofia governorate.

\subsection{Aim of the study}

To assess the nurse managers' behavior in managing change and the level of the organizational change readiness at selected hospitals at Menofia Governorate.

\subsection{Research questions}

(1) What is the nurse managers' behavior in the managing change from her perspective?

(2) What is the nurse managers' behavior in managing change from staff nurses' perspective?

(3) What is the level of organizational change readiness as reported by the study subjects?

(4) Is there a relationship between organizational change readiness and nurse manager' behavior in managing change?

\subsection{Theoretical framework}

The most common models of change are the change model of Lewin ${ }^{[13]}$ who reported that organizational change includes a move from one standing state by means of a progression shift, to another standing state. The model consists of a threestage namely: unfreezing, moving, and re-freezing stage (see Figure 1).
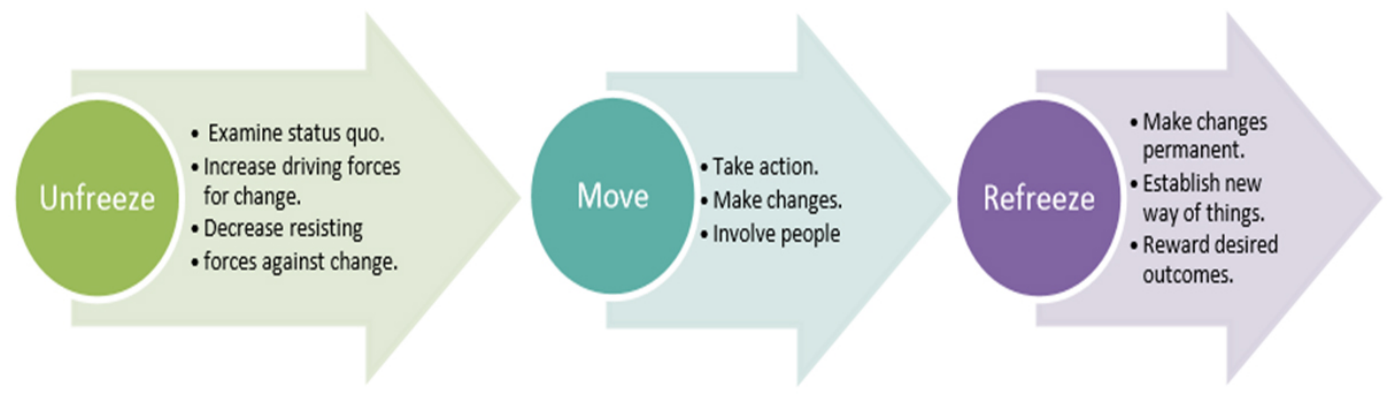

Figure 1. Kurt Lewin's 3 step model

\section{SUBJECTS AND METHODS}

\subsection{Research design}

A descriptive cross-sectional research design was utilized.

\subsection{Setting}

The study is conducted in two hospitals, namely University Hospital and Shebin El-Kom Teaching Hospital, at Menofia Governorate, Egypt.

\subsection{Subjects}

The subjects included in the study composed of two groups:

Group 1: Staff nurses A convenience sample of 136 staff nurses (67 staff nurses from Menofia University Hospital, and 69 from Shebin El-Kom Teaching Hospital). That meets the criteria such as having working experience not less than three years and agrees to participate in this study.

Group 2: Nurse manager All nurse managers available at the time of the study will be included (31 nurse managers from Menofia University Hospitals, and 30 nurse managers from Shebin El-Kom Teaching Hospital).

\subsection{Data collection tools}

Tool one: An interview questionnaire sheet was adapted by the researchers and includes two parts:
Part I: This part contains socio-demographic data as hospital name, age, nursing qualification, and years of experience in nursing.

Part II: Change Management Process Questionnaire

It was adapted from Francis's study. ${ }^{[14]}$ It was designed to assess nurse managers' behavior during management of change, and also to assess staff nurses' opinions toward manager' behavior in managing change in the organization. It consisted of (60) questions using a (Three-point Likert scale). This questionnaire was subdivided into four dimensions which are: use of a change management process (15 items), level of change management process skills (15 items), application of change management process knowledge (15 items), and beliefs about Change (15 items).

Scoring system: The participants were asked to indicate their agreement or disagreement with the questionnaire statements by using a 3-point Likert scale ranging from "disagree", scored 1 point, to "agree", scored 3 points. The total score was ranged from (60-180), and a total score of each dimension is calculated. The total change management process score is the sum of the scores of all the dimensions. A high score indicates that the managers had a good behavior in managing change in the organization. 
Tool two: Change Readiness Assessment Scale. It was designed to assess readiness level to change in the organization. It was developed by WorkLife Design. ${ }^{[15]}$ The scale was translated into Arabic and modified by the researchers. It consisted of 20 items.

Scoring system: The participants were asked to indicate their agreement or disagreement with the questionnaire statements by using a 3-point Likert scale in which disagree item was assigned a score of "one", uncertain item was assigned a score of "two", and agree item was assigned a score of "three". The total score was ranged from 20 to 60 , and a total score of each dimension is calculated. A high score indicates that the organization has the great level of change readiness.

\subsection{Validity and reliability of the instrumentation 2.5.1 Validity}

Tools of data collection were translated into Arabic and tools were revised for content validity by 5 experts in the related field.

\subsubsection{Reliability}

The tools were tested for reliability by using Cronbach's alpha coefficient ( $\alpha=0.92)$ for change management process tool, and $(\alpha=0.90)$ for change readiness assessment tool. The tools were clear, comprehensive, and applicable.

\subsection{Pilot study}

A pilot study was carried out with $10 \%$ of the sample who were not included in the main study sample. It was done to test the clarity of the study tools. The average time needed to complete the Change Management Process questionnaire was ranged between 20-25 minutes and Change Readiness Assessment Scale ranged from 10-15 minutes. The necessary modification was done.

\subsection{Field work}

Data was collected upon two months starting from first of March 2017 until the end of April 2017. This was done weekly in the morning and afternoon shifts. After gaining the acceptance from nurses and nurse managers to participate in the study, the researcher explained the purpose and content of the tool to nurses and nurse managers and asked to fill it out and return it anonymously in the same day or at most the next day. The researchers were available for any clarifications.

\subsection{Ethical consecrations}

Written approval was obtained from the faculty of nursing clarifying the purpose of the study to the two hospitals directors to conduct the study and collect the necessary data.
Participants' consent to participate was obtained after informing them about their rights to participate, refuse, or withdraw at any time without any harmful effect during or after sessions.

\subsection{Statistical analysis}

The data were collected and tabulated into the personal computer. Statistical analysis was done using Statistical Package for Social Science (SPSS/version 23). Quantitative data were expressed as the mean \& standard deviation $(\bar{X} \pm \mathrm{SD})$. Qualitative data were expressed as number and percentage. $P$-value at .05 was used to determine the level of significance.

\section{RESUlts}

Table 1 shows socio-demographic characteristics of the studied groups. As shown in the table, the nearly equal percentage of the studied groups was from teaching and university hospital. Regarding age, less than half of staff nurses and nurse managers ranged from 30 to less than 39 years $(42.6 \%$ \& $31.6 \%$ respectively). Concerning qualification, the majority of nurse managers $(83.8 \%)$ had a bachelor degree in nursing and half of staff nurses $(50.8 \%)$ had a diploma. Regarding years of experience, the highest percentage of the studied subjects (staff nurses and nurse managers) had experience from 5 to 10 years $(36.1 \% \& 52.2 \%$, respectively).

Table $2 \&$ Figure 2 represent behavior of the nurse manager in managing change from the study subjects' perspective. From the nurse managers' perspective, the highest percentage of nurse managers had a good behavior in managing change (75.4\%). In contrast, the highest percentage of staff nurses reported from their perspective that nurse managers had a bad behavior in managing change.

Table $3 \&$ Figure 3 represent the behavior of nurse manager during managing change from the study subjects' perspective according to hospitals. As indicated in the table, the highest percentage reported that nurse managers had a good behavior in managing change process in University hospital than in the Teaching hospital $(61.2 \% \& 31.3 \%)$, respectively. Additionally, there was a statistically significant difference between the study settings regarding the behavior of nurse manager during managing change in the organization.

Table 4 illustrates mean score of aspects of managing change from the study subjects' perspective. As presented in Table 4 , the mean score of study subjects' regarding managing change aspects was higher in university hospital than teaching hospital. Moreover, there were statistically significant differences between the study settings regarding all aspects of managing change except the use of change management process. 
Table 1. Socio-demographic characteristics of the studied groups $(\mathrm{n}=197)$

\begin{tabular}{|c|c|c|c|c|}
\hline \multirow{3}{*}{ Socio demographic data } & \multicolumn{4}{|c|}{ Total sample (197) } \\
\hline & \multicolumn{2}{|c|}{ Nurse manager (61) } & \multicolumn{2}{|c|}{ Staff nurse (136) } \\
\hline & No. & $\%$ & No. & $\%$ \\
\hline Hospital & & & & 50.7 \\
\hline Teaching Hospital & 30 & 49.2 & 69 & 49.3 \\
\hline University Hospital & 31 & 50.8 & 67 & \\
\hline \multicolumn{5}{|l|}{ Age } \\
\hline $18-29$ yrs & 24 & 39.3 & 42 & 30.9 \\
\hline $30-39$ yrs & 26 & 42.6 & 43 & 31.6 \\
\hline $40-49$ yrs & 10 & 16.4 & 29 & 21.3 \\
\hline$\geq 50 \mathrm{yrs}$ & 1 & 1.6 & 22 & 16.2 \\
\hline \multicolumn{5}{|l|}{ Qualification } \\
\hline Bachelors degree & 29 & 47.5 & & \\
\hline Diploma & 31 & 50.8 & 114 & $\begin{array}{l}83.8 \\
162\end{array}$ \\
\hline Master degree & 1 & 1.6 & 22 & 16.2 \\
\hline \multicolumn{5}{|l|}{ Experience years } \\
\hline$<5 \mathrm{yrs}$ & 19 & 31.1 & 26 & 19.1 \\
\hline $5-10$ yrs & 22 & 36.1 & 71 & 52.2 \\
\hline$>10 \mathrm{yrs}$ & 20 & 32.8 & 39 & 28.7 \\
\hline
\end{tabular}

Table 2. Behavior of nurse manager in managing change from the study subjects' perspective $(n=197)$

\begin{tabular}{|c|c|c|c|c|c|c|}
\hline \multirow{3}{*}{ Nurse manager behavior } & \multicolumn{4}{|c|}{ Studied sample (197) } & \multirow{3}{*}{ Chi-square } & \multirow{3}{*}{$p$-value } \\
\hline & \multicolumn{2}{|c|}{ Nurse manager (61) } & \multicolumn{2}{|c|}{ Staff nurse (136) } & & \\
\hline & No. & $\%$ & No. & $\%$ & & \\
\hline Good behavior $(\geq 70 \%)$ & 35 & 57.4 & 56 & 41.2 & \multirow{2}{*}{4.447} & \multirow{2}{*}{.035} \\
\hline Bad behavior $(<70 \%)$ & 26 & 42.6 & 80 & 58.8 & & \\
\hline
\end{tabular}

\section{Bar Chart}

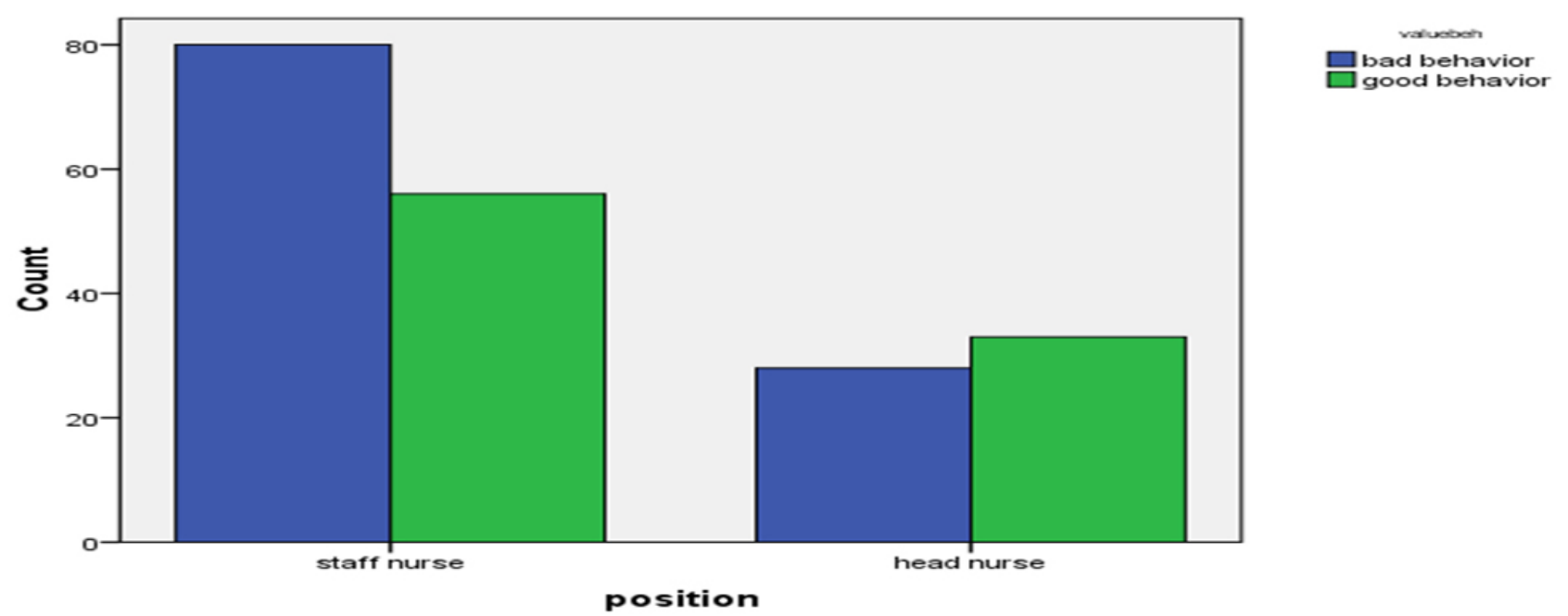

Figure 2. Behavior of nurse manager in managing change from the study subject perspective

Table 5 demonstrates organizational change readiness level as reported by study subjects. As indicated from the table, the highest percentage of the study subject had a bad readiness level to change $(60.7 \%$ \& $88.2 \%)$, respectively. Additionally, there was a statistically significant difference between nurse managers and staff nurses regarding change readiness. 
Table 3. Behavior of nurse manager during managing change from the study subject' perspective according to hospitals (n =197)

\begin{tabular}{|c|c|c|c|c|c|c|}
\hline \multirow{3}{*}{ Nurse manager behavior } & \multicolumn{4}{|c|}{ Study Setting } & \multirow{3}{*}{ Chi-square } & \multirow{3}{*}{$p$-value } \\
\hline & \multicolumn{2}{|c|}{$\begin{array}{l}\text { Teaching hospital } \\
(\mathrm{n}=99)\end{array}$} & \multicolumn{2}{|c|}{$\begin{array}{l}\text { University hospital } \\
(\mathrm{n}=98)\end{array}$} & & \\
\hline & No. & $\%$ & No. & $\%$ & & \\
\hline Good behavior $(\geq 70 \%)$ & 31 & 31.3 & 60 & 61.2 & \multirow{2}{*}{17.728} & \multirow{2}{*}{$.000^{*}$} \\
\hline Bad behavior $(<70 \%)$ & 68 & 68.7 & 38 & 38.8 & & \\
\hline
\end{tabular}

\section{Bar Chart}

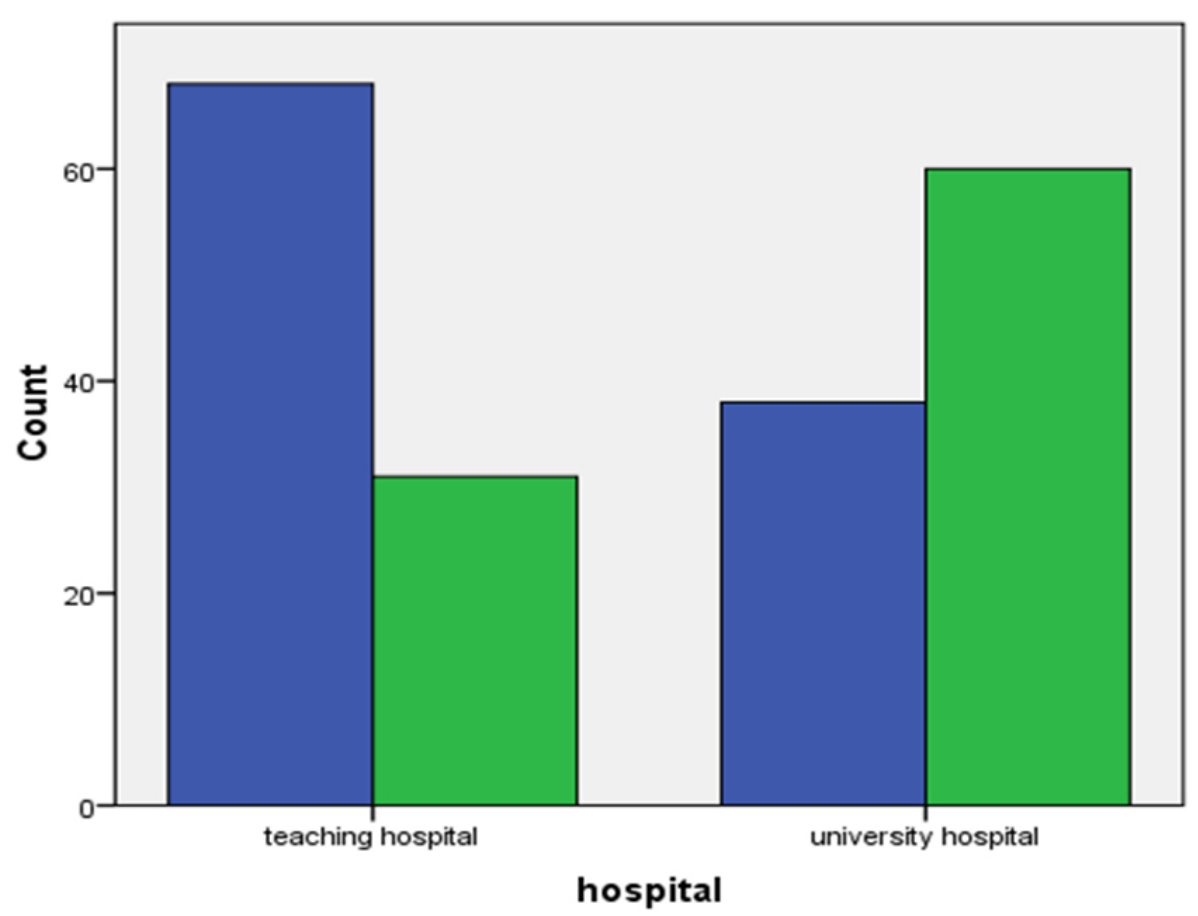

Figure 3. Behavior of nurse manager during managing change from the study subjects' perspective according to hospitals

Table 4. Mean score aspects of managing change from the study subjects' perspective $(n=197)$

\begin{tabular}{|c|c|c|c|c|}
\hline \multirow{3}{*}{ Managing Change aspect } & \multicolumn{2}{|c|}{ Studied sample $(\mathrm{n}=197)$} & \multirow{3}{*}{$t$-test } & \multirow{3}{*}{$p$-value } \\
\hline & $\begin{array}{l}\text { Teaching hospital } \\
(\mathrm{n}=61)\end{array}$ & $\begin{array}{l}\text { University hospital } \\
(n=136)\end{array}$ & & \\
\hline & Mean \pm SD & Mean \pm SD & & \\
\hline Use of change management process & $26.82 \pm 9.77$ & $29.44 \pm 10.02$ & 1.859 & .065 \\
\hline Level of change management skills & $26.03 \pm 9.9$ & $29.12 \pm 9.9$ & -2.176 & .031 \\
\hline Application of change management knowledge & $25.71 \pm 10.73$ & $29.21 \pm 11.08$ & -2.249 & .026 \\
\hline Beliefs about change & $26.39 \pm 10.12$ & $30.64 \pm 11.08$ & -2.811 & .005 \\
\hline
\end{tabular}

Table 6 shows organizational change readiness level as reported by study subjects according to hospitals. As observed from the table, the highest percentage of study subjects reported that the organization had a bad level of change readi- ness in both hospitals (98.9\% \& 69.4\%). As noticed from the table, there was a statistically significant difference between two hospitals regarding the perception of readiness level to change in the organization. 
Table 5. Organizational change readiness level as reported by study subject $(\mathrm{n}=197)$

\begin{tabular}{|c|c|c|c|c|c|c|}
\hline \multirow{3}{*}{ Change Readiness Level } & \multicolumn{4}{|c|}{ Study Subject (197) } & \multirow{3}{*}{ Chi-square } & \multirow{3}{*}{$p$-value } \\
\hline & \multicolumn{2}{|c|}{ Nurse manager (61) } & \multicolumn{2}{|c|}{ Staff nurse (136) } & & \\
\hline & No. & $\%$ & No. & $\%$ & & \\
\hline Great readiness $(\geq 70 \%)$ & 24 & 39.3 & 16 & 11.8 & 10705 & 000 \\
\hline Bad readiness $(<70 \%)$ & 37 & 60.7 & 120 & 88.2 & 19.195 & . .000 \\
\hline
\end{tabular}

Table 6. Organizational change readiness level as reported by study subject according to hospitals

\begin{tabular}{|c|c|c|c|c|c|c|}
\hline \multirow{3}{*}{ Change Readiness Level } & \multicolumn{4}{|c|}{ Hospital } & \multirow{3}{*}{ Chi-square } & \multirow{3}{*}{$p$-value } \\
\hline & \multicolumn{2}{|c|}{$\begin{array}{l}\text { Teaching hospital } \\
(\mathbf{n}=99)\end{array}$} & \multicolumn{2}{|c|}{$\begin{array}{l}\text { University hospital } \\
(\mathrm{n}=98)\end{array}$} & & \\
\hline & No. & $\%$ & No. & $\%$ & & \\
\hline Great readiness $(\geq 70 \%)$ & 10 & 10.1 & 30 & 30.6 & \multirow{2}{*}{3.674} & \multirow{2}{*}{.000} \\
\hline Bad readiness $(<70 \%)$ & 89 & 98.9 & 68 & 69.4 & & \\
\hline
\end{tabular}

Table 7 demonstrates a correlation between organizational change readiness and manager behavior in managing change among study subjects. As shown in the table, there was a positive correlation between organizational change readiness and manager behavior in managing change $(r=0.154 \& p=$ $.03)$.

Table 7. Correlation between organizational change readiness and manager behavior in managing change among study subject $(\mathrm{n}=197)$

\begin{tabular}{lll}
\hline $\begin{array}{l}\text { Organizational } \\
\text { change readiness }\end{array}$ & \multicolumn{2}{l}{ Manager behavior } \\
\cline { 2 - 3 } & $\boldsymbol{R}$ & $\boldsymbol{p}$ \\
\hline$* p<.05$ & 0.154 & $.031^{*}$ \\
\hline
\end{tabular}

\section{Discussion}

In fact, a key competency for healthcare managers was managing organizational change. It is important to manage the change process within public health organizations because this is related to improved organizational performance. However, change is difficult and the change process poses formidable challenges for managers Thompson. ${ }^{[16]}$ Managers are at the top level of the organization and they give authority and credibility to the successful implementation of change.

Therefore, the aim of the present study was to assess the nurse managers' behavior in managing change and the level of the organizational change readiness at selected hospitals at Menofia Governorate. Four questions were answered in the present study. The first question was what is the nurse manager behavior in the managing change from her perspective? The second was what is the nurse managers' behavior in the managing change from staff nurses' perspective? The third was what is the level of organizational change readiness as reported by all study subjects? The final one what is there a relationship between organizational change readiness and manager' behavior in managing change?

Before discussing the results related to answering the study questions, light ought to be coordinated to sociodemographic characteristics of the studied groups that delineated in the Table 1. The present study was directed at two hospitals; Menofia University Hospitals and Shebin El-Kom Teaching Hospital. As shown in the table, the nearly equal percentages of the study subjects were from teaching and university hospital. Regarding age, less than half of staff nurses and nurse managers ranged from 30 to less than 39 years ( $42.6 \% \& 31.6 \%$ respectively). Concerning qualification, the majority of nurse managers ( $83.8 \%$ ) had a bachelor degree in nursing and half of staff nurses $(50.8 \%)$ had a diploma. Regarding years of experience, the highest percentage of the studied subjects (staff nurses and nurse managers) had experience from 5 to 10 years $(36.1 \% \& 52.2 \%$, respectively).

The most important result in the present study was that the majority of nurse managers perceived good behavior in managing the change process. This finding is reassuring because half of the studied nurse managers had a bachelor degree in nursing. From the researcher perspective, this result may be explained by the fact that they prepared during their study in college how to deal with change through studying change, causes of change, and steps to manage change process and how to deal with resistance in a good manner. So, they can apply this very easily and deal with resistance professionally. Additionally, everyone sees himself as the best in doing things. Therefore, nurse managers reported that they deal in the good manner during the change process.

This result is similar to Siddiqui ${ }^{[17]}$ who pointed out that assistance from the top management is very significant because 
it helps the employees to implement their innovative and creative ideas and help to effectively manage the organization change as well. In addition, Katsaros et al. ${ }^{[18]}$ reported that management should focus on both the timing and the amount of information disseminated as well as the training received regarding the planned change; to influence positively the employee attitudes towards the proposed organizational change. As a result, open communication, early training, and transparency of the process may facilitate employee understanding of the changing purpose and allow them to progress more quickly towards change acceptance.

Additionally, These findings were supported by Ionescu, Merut, Dragomiroiu, ${ }^{[7]}$ who identified that managers are at the highest level of the organization must, at all times, to demonstrate that they are personally committed to changes that take place. Also, Muhammad et al. ${ }^{[19]}$ found that middle and front-line managers have more discretionary power to implement further changes for having better performance. The findings of this study showed that there exists a significant and positive relationship between leader-member exchange and organizational change management.

On the other hand, more than half of staff nurses reported that their nurse managers had a bad behavior during managing change. From the researcher perspective, this finding may be attributed to the probability of lack of support of top management, and lack of clear information or poor communication during the change process. Therefore, many nurses may become dissatisfied, less committed to their healthcare organization and less motivated to participate in any change program. So, they perceive their nurse manager behavior as bad during the change process. This result is congruent with Howard ${ }^{[20]}$ who argued that change is a source of threats to employees and emotions help in dealing with these threats, set new goals and learn new behavior. In this respect, most nurses perceived negative high control emotional climate (envy, disgust, contempt, and anger) with high intensity. This is could be due to nurses are dissatisfied with their job due to many causes as work overload, inadequate resources and salaries, poor relationships in the workplace and moderate access to a subset of structure empowerment. All these reasons cause nurses' stress which leads to evolving of negative emotions toward their organization.

Results regarding the behavior of nurse managers in managing change were higher at university hospital than teaching hospital. The study subjects in the university hospital reported that nurse managers had a good behavior in managing change than nurse manager in a teaching hospital. From the researcher perspective, this result might be due to the highest percentage of nurses in a teaching hospital are diploma nurses and also they usually have limited resources about managing change process when compared to the university hospital where the highest percentage of nurses are bachelor degree nurses and have more access to resources. This result is a similar line with Vakola et al. ${ }^{[21]}$ who showed that people will not perform well in change initiatives when they are not confident about their abilities. In addition, Oreg et al. ${ }^{[22]}$ explained that perceived benefit or harm of the change at hand has an impact on change recipients' job satisfaction levels, stress levels, psychological states, openness to accept change, post-change job attitudes, etc.

Organizational readiness for change is a multilevel construct that can be assessed at the individual or supra-individual levels (e.g., team, department, or organization). ${ }^{[23]}$ The present study has revealed that the highest negative responses by staff nurses and nurse managers for readiness of their organization to change. The nurse managers and staff nurses reported that the organization had a bad readiness level to change. In the same time, readiness level to change was bad in the teaching hospital than in the university hospital as reported by the majority of the study subjects. From the researcher perspective, This result caused by wasting opportunities and resources, sometimes referred to as change risk assessments., the interrelatedness of all parts in a functioning system, and also defect in the ability to manage change, which requires several capacities such as communication skills, flexibility and responsiveness, strategic thinking and so on. On the contradicting with the present findings, the results of Shah ${ }^{[24]}$ who found that high readiness for organizational change. Also, Zayim and Kondakci ${ }^{[25]}$ stated that readiness for change is one of the constructs that fosters positive behavior, attitudes and thinking towards new adjustments on the part of employees. Additionally, readiness for change is regarded as a critical factor in the success of change initiatives Rafferty, Jimmieson, \& Armenakis. ${ }^{[26]}$

Regarding the relation between organizational change readiness and nurse managers' behavior in managing change, a positive correlation was found between organizational change readiness and manager behavior in managing change. Additionally, this result was congruent with Weiner ${ }^{[27]}$ who stated that when organizational readiness is high, members are more likely to launch change, do the greater effort, exhibit greater insistence, and display more cooperative behavior, which overall leads to the more effective implementation of the proposed change. Conversely, when organizational readiness is low, members are more likely to view the change as undesirable and subsequently avoid, or even resist, planning for the effort and participating in the change process. 


\section{Conclusion}

This study concluded that the majority of nurse managers had good behavior in managing change process from their perspective while more than half of staff nurses reported that their nurse managers had a bad behavior during managing change. And also the nurse managers and staff nurses reported that the organization had a bad readiness level to change. Additionally, there was a positive correlation between organizational change readiness and manager behavior in managing change.

\section{Recommendations}

In light of the findings, it may be recommended the following:

(1) The organization should have a readiness for change to support the change process by possessing the right resources and conditions, a clear vision and objectives for the change wanted and having the motivation and attitudes to engage with the change and make it work.

(2) Change leaders should lead a team who has the courage to drive change properly in an existing system.

(3) Chiefs and management as agents of change must need to drive a strong reaction for change from the stakeholders that leads to highest performance improvement.

(4) In-service training should be conducted to nurse managers in how to manage change more professionally.

(5) More researches are needed to identify factors that affect manager behavior during management of change process.

(6) More researches are needed to identify the influence of change management on the providing high quality of care.

\section{CONFLiCTS OF InTEREST Disclosure}

The authors declare that there is no conflict of interest.

\section{REFERENCES}

[1] Lee J. Aligning organizations for positive change: the role of leadership in matching strategy, culture, and social networks to vital organizational challenges. Advances in Global Leadership. 2011; 6(1): 71-94. Available from: http://www. emeraldinsight.com/doi /pdfplus/10.1108/S1535-1203\%282011\%290000006007

[2] İkinci S. Organizational Change: Importance of Leadership Style and Training. Management and Organizational Studies. 2014; 1(2): 122-128. Available from: http://www. sciedu.ca/journal/in dex.php/mos/article/view/5336/3115

[3] Sidra A, Zuhair F, Noman S, et al. Role of Leadership in Change Management Process. Abasyn Journal of Social Sciences. 2013; 5(2): 111-124.

[4] Singh K. Leadership \& Organizational Learning in Knowledge Management Practices in Global Organizations. The Indian Journal of Industrial Relations. 2011; 47(2): 353-365.

[5] Smith I. Continuing professional development and workplace learning. Library Management. 2006; 27(4/5): 300-306.

[6] Ionescu EI, Meruţă A, Dragomiroiu R. Role of managers in management of change. Procedia Economics and Finance. 2014; 16: 293-298. https://doi.org/10.1016/S2212-5671(14)00804-1

[7] Randhawa S. Using the Transtheoretical Model for Outcome Evaluation in Continuing Education. Journal of Continuing Education in Nursing. 2012; 43(4): 148-9.

[8] Bryan J. A theory of organizational readiness for change. BioMed Central. 2009. https://doi.org/10.1186/1748-5908-4-67

[9] Pearson J. Training and Beyond: Seeking Better Practices for Capacity Development. OECD Development Cooperation Working Papers. 2011. Available from: http: //www.oecd-ilibrary.org/development/training-andbe yond-seeking-better-practices-for-capacity-develop ment_5kgf1nsnj8tfen; jsessionid=4ld21rkgpd5gq. delta https://doi.org/10.1787/5kgf1nsnj8tf-en

[10] Tunçer P. Organizational change and leadership. Journal of Court of Accounts. 2011; 80: 57-83.
[11] Bejestani H. Improving Project Change Management Using Leadership Spirit. I Business. 2011; 3(3): 302-306.

[12] Willmott H. Rethinking management and managerial work: capitalism, control, and subjectivity. Human Relations. 1997; 50(11): 1329-59.

[13] Lewin K. Field Theory in Social Science. New York: Harper \& Row. 1951.

[14] Francis J. Successfully Managing Change -Change Management Profile Questionnaire and Interpretive Notes. 60 Successfully Managing Change. 2015.

[15] WorkLife Design. How to assess change readiness. 2008.

[16] Thompson J. Understanding and Managing Organizational Change: Implications for Public Health Management. Journal of Public Health Management \& Practice. 2010; 16(2): 167-173.

[17] Siddiqui F. Impact of Employee's Willingness on Organizational Change. Journal of Economics and Sustainable Development. 2011; 2(4): 193-201.

[18] Katsaros K, Tsirikas A, Bani S. Exploring Employees' Perceptions, Job-Related Attitudes, and Characteristics during a Planned Organizational Change. Journal of Business Science and Applied Management. 2014; 9(1): 36-49.

[19] Muhammad A, Sarwar Z, Uzma K, et al. Role of leader-member exchange relationship in organizational change management: Mediating role of organizational culture. International Journal of Organizational Leadership. 2017; 6(1): 32-41.

[20] Howard A. Positive and Negative Emotional Attractors and Intentional Change. Journal of Management Development. 2006; 25(7): 657-670.

[21] Vakola M, Oreg S, Armenakis A. Reactions to organizational change from an individual-differences perspective: a review of empirical research", in Oreg, S., Michel, A., and By. R. (Eds), The Psychology of Organizational Change: Viewing Change from the Employee's Perspective, Cambridge University Press; 2013. 95-123 p. 
[22] Oreg S, Vakola M, Armenakis A. Change recipients' reactions to organizational change: a sixty-year review of quantitative studies. Journal of Applied Behavioural Science. 2011; 47(4): 461-524.

[23] Shea C, Jacobs S, Esserman D, et al. Organizational readiness for implementing change: a psychometric assessment of a new measure. Implementation Science. 2014. https://doi.org/10.1186/17 48-5908-9-7

[24] Shah N. Determinants of Employee Readiness for Organizational Change. Published Doctoral Dissertation. Brunel Business School. Brunel University. 2009.

[25] Zayim M, Kondakci Y. An Exploration of the Relationship between
Readiness for Change and Organizational Trust in Turkish Public Schools. Journal of Educational Management Administration \& Leadership. 2015; 43(4): 610-625. https://doi.org/10.1177/1741 143214523009

[26] Rafferty A, Jimmieson N, Armenakis A. Change readiness: A multilevel review. Journal of Management. 2013; 39(1): 110-135. Available from: https://eps644.wikispaces.com/file/view/Mu ltilevel+Review+of+Change+Readiness.pdf

[27] Weiner BJ, Lewis MA, Linnan LA. Using organization theory to understand the determinants of effective implementation of worksite health promotion programs. Health Education Research. 2009; 24(2): 292-305. 